\title{
The use of antibiotics in treatment of acute COPD exacerbations does not adhere to national guidelines
}

\author{
Hanne Nielsen ${ }^{*}$, Marianne Lund Gudik-Sørensen², Karen Egholt Søgaard ${ }^{3}$, Mie Visby Dyrholm ${ }^{4}$ \\ From Danish Society for Emergency Medicine: Research Symposium 2010 \\ Roskilde, Denmark. 20-21 May 2010
}

\section{Background}

Acute chronic obstructive pulmonary disease (COPD) exacerbation is a serious condition with a mortality of $10 \%$, and the condition often require treatment with antibiotics.

The aims of the study were 1) to evaluate which antibiotics, the physicians prescribe in first line treatment to patients with acute COPD exacerbation, and 2) to compare the given treatments with national guidelines.

\section{Methods}

The study included 100 randomly selected patient charts; 25 from each of the 4 emergency wards in Region Sjælland (Køge, Slagelse, Nykøbing Falster and Holbæk).

Data were collected retrospectively from electronic charts in the period August-December 2009.

Inclusion criteria were COPD patients older than 18 years with acute exacerbation of COPD, need for antibiotics, no concurrent treatment with chemotherapy or immunosuppressive drugs admitted to the emergency wards.

The national guidelines included guidelines from the Danish Society of Respiratory Medicine, Medicin.dk, Institute for Rational Pharmacotherapy and the Danish College of General Practitioners.

\section{Results}

The study showed that cefuroxime, benzylpenicillin and amoxicillin in combination with clavulanic acid were the most frequently used antibiotics for the treatment of acute COPD exacerbation.

In total, $82 \%$ of the patients received intravenous antibiotic treatment exclusively. Of these patients, $73 \%$ were treated with cefuroxime and $27 \%$ with benzylpenicillin.

\footnotetext{
* Correspondence: hni@regionsjaelland.dk

${ }^{1}$ Region Sjælland Sygehusapoteket, Roskilde, Denmark

Full list of author information is available at the end of the article
}

Oral antibiotics were used in $17 \%$ of the patients. Of these, $88 \%$ were treated with amoxicillin in combination with clavulanic acid and $12 \%$ with phenoxymethylpenicillin. One patient was treated with cefuroxime in combination with oral azithromycin.

The national guidelines recommend cefuroxime as first choice drug in hospital treatment of acute COPD exacerbation.

\section{Conclusion}

Cefuroxime was the most commonly used antibiotic in the treatment of acute COPD exacerbation. According to national guidelines, benzylpenicillin is not recommended for the treatment of acute COPD exacerbations. However, this antibiotic was used in $27 \%$ of the patients.

Consequently, the results indicate a need for a regional guideline composed in co-operation with specialists in Infectious Disease, Clinical microbiology and Pulmonary disease.

This will help the physicians choosing the right treatment, and contribute to standardized treatment of patients with acute COPD exacerbation in Region Sjælland.

\section{Author details}

${ }^{1}$ Region Sjælland Sygehusapoteket, Roskilde, Denmark. ${ }^{2}$ Region Sjælland Sygehusapoteket, Holbæk, Denmark. ${ }^{3}$ Region Sjælland Sygehusapoteket, Slagelse, Denmark. ${ }^{4}$ Region Sjælland Sygehusapoteket, Næstved, Denmark.

Published: 17 September 2010

doi:10.1186/1757-7241-18-S1-O3

Cite this article as: Nielsen et al:: The use of antibiotics in treatment of acute COPD exacerbations does not adhere to national guidelines. Scandinavian Journal of Trauma, Resuscitation and Emergency Medicine 2010 18(Suppl 1):O3. 